\title{
Effect of peer support interventions on cardiovascular disease risk factors in adults with diabetes: a systematic review and meta-analysis
}

Sonal J. Patil ${ }^{1 *}$ (D) Todd Ruppar², Richelle J. Koopman ${ }^{1}$, Erik J. Lindbloom¹, Susan G. Elliott ${ }^{1}$, David R. Mehr ${ }^{1}$ and Vicki S. Conn ${ }^{3}$

\begin{abstract}
Background: Peer support by persons affected with diabetes improves peer supporter's diabetes self-management skills. Peer support interventions by individuals who have diabetes or are affected by diabetes have been shown to improve glycemic control; however, its effects on other cardiovascular disease risk factors in adults with diabetes are unknown. We aimed to estimate the effect of peer support interventions on cardiovascular disease risk factors other than glycemic control in adults with diabetes.

Methods: We conducted a systematic review and meta-analysis of randomized controlled trials comparing peer support interventions to a control condition in adults affected by diabetes that measured any cardiovascular disease risk factors [Body Mass Index, smoking, diet, physical activity, cholesterol level, glucose control and blood pressure]. Quality was assessed by Cochrane's risk of bias tool. We calculated standardized mean difference effect sizes using random effects models.

Results: We retrieved 438 citations from multiple databases including OVID MEDLINE, Cochrane database and Scopus, and author searches. Of 233 abstracts reviewed, 16 articles met inclusion criteria. A random effects model in a total of 3243 participants showed a positive effect of peer support interventions on systolic BP with a pooled effect size of 2. $07 \mathrm{mmHg}(\mathrm{Cl} 0.35 \mathrm{mmHg}$ to $3.79 \mathrm{mmHg}, p=0.02)$; baseline pooled systolic blood pressure was $137 \mathrm{mmHg}$. There was a non-significant effect of peer support interventions on diastolic blood pressure, cholesterol, body mass index, diet and physical activity. Cardiovascular disease risk factors other than glycemic control outcomes were secondary outcomes in most studies and baseline values were normal or mildly elevated. Only one study reported smoking outcomes.

Conclusions: We found a small $(2 \mathrm{mmHg}$ ) positive effect of peer support interventions on systolic blood pressure in adults with diabetes whose baseline blood pressure was on average minimally elevated. Additional studies need to be conducted to further understand the effect of peer support interventions on high-risk cardiovascular disease risk factors in adults with diabetes.
\end{abstract}

Keywords: Peer support, Diabetes, Cardiovascular health metrics, Self-management, Blood pressure, Physical activity, Behavioral counseling

\footnotetext{
* Correspondence: patilso@health.missouri.edu

${ }^{1}$ Curtis W. and Ann H. Long Department of Family and Community

Medicine, University of Missouri, MA306 Medical Sciences Building, DC032.00,

Columbia, MO 65212, USA

Full list of author information is available at the end of the article
} 


\section{Background}

In the last decade, several trials have looked at the effects of peer support interventions in adults with diabetes; several of these have looked at changes in cardiovascular disease risk factors. Diabetes increases cardiovascular disease (CVD) risk by twofold, and, in patients with type 2 diabetes, cholesterol and blood pressure lowering appear more important than glucose lowering in reducing cardiovascular events $[1,2]$. The American Heart Association (AHA) introduced the concept of cardiovascular health characterized by seven ideal metrics namely Body Mass Index (BMI), smoking, diet, physical activity, cholesterol level, blood pressure and glucose levels, to improve the cardiovascular health of all Americans while reducing deaths from CVD and strokes [3, 4]. These metrics are also known as Life's Simple 7 [3]. Several studies and a 2016 systematic review of population studies found an inverse relationship between an increasing number of ideal AHA cardiovascular health metrics and all-cause mortality, CVDrelated mortality, incidence of stroke, and incidence of non-CVD outcomes such as cancer, depression and cognitive decline [5-7]. A 2014 systematic review for the U. S. Preventive Services Task Force (USPSTF) showed that intensive behavioral counseling for diet and physical activity in people with CVD risk factors resulted in improvements in cholesterol, blood pressure and fasting glucose levels [8]. Peer support interventions could be a sustainable community-based intervention for behavioral counseling in people with CVD risk factors.

A 2010 systematic review of peer-support intervention trials for individuals with heart disease did not find studies reporting clinical outcomes or CVD risk factor outcomes [9]. However, there have been several randomized controlled trials (RCTs) of peer support interventions in people affected by diabetes looking at diabetes and cardiovascular disease risk factor outcomes. Several systematic reviews have shown improved glycemic outcomes with peer support interventions [10-12]; however, to date, there have been no systematic reviews and metaanalyses synthesizing the effect of peer support interventions on cardiovascular disease risk factors other than glycemic control in adults with diabetes. Consequently, we conducted a systematic review and meta-analysis of randomized controlled trials to assess the effectiveness of peer support interventions on cardiovascular disease risk factors other than glucose control in adult patients with diabetes compared to otherwise similar care.

We have defined peer support as support from a person who has knowledge from their own experiences with a chronic condition, which in our study is diabetes. This definition is from of the American Academy of Family Physicians (AAFP) Peers for Progress program [13]. Being a peer supporter empowers patients to improve their diabetes self-management skills while incorporating personal experiences to empathize with other affected individuals [14]. A qualitative study of peer leaders in a study that compared peer-delivered versus professionally delivered hypertension self-management education showed that peer leaders noted improvements in their own systolic blood pressure, hypertension knowledge, pedometer use and fruit and vegetable intake [15]. We chose the AAFP Peers for Progress program definition of peer support because engaging individuals affected with chronic conditions in intervention delivery to people affected by similar conditions may further enhance patient engagement in self-management behaviors.

\section{Methods}

We have used the PRISMA statement and reporting system for reporting the findings of our systematic review [16].

\section{Search strategy and study selection}

Randomized controlled trials of peer-support interventions compared to otherwise similar care in adult patients with diabetes that measured any of the cardiovascular disease risk factors (BMI, smoking, diet, physical activity, cholesterol level, blood pressure and glucose levels) as primary or secondary outcomes were included. Studies with adult participants affected with any type of diabetes were included. We used the AAFP Peers for Progress definition of peer support which is support from a person with diabetes or a person affected by diabetes [13]. Studies were excluded if the intervention group received any additional care other than peerdelivered intervention compared to control group. Studies with peer support intervention facilitators where the facilitators were professionals or not affected by diabetes were excluded. Studies comparing a peer-delivered intervention to an identical intervention delivered by other health professionals were excluded as well. The only difference between the intervention and the control group had to be a peer-delivered intervention. We made this choice because our goal was to understand the added value of peer support to usual care rather than how peer support compared to other support interventions.

\section{Data sources}

To ensure a comprehensive review, we did separate searches for papers involving peer support and diabetes and peer support and cardiovascular risk factors. We initially searched multiple databases, including Ovid MEDLINE, the Cochrane Central Register of Controlled Trials, Scopus, CINAHL, PsycINFO, OCLC First Search, and a few others for English and non-English articles from January 1960 through November 2015. Groups of search terms included diabetes mellitus; RCT; peer support, promotora, peer educator, peer coach; HbA1C. We 
additionally, searched Ovid Medline and Scopus for English articles from January 1990 to August 2016 with additional search terms. Groups of search terms for the second search included peer health, peer support, peer counselor, peer adviser, peer coach, promotora; hypertension, high blood pressure, cardiovascular, cardiac, heart, vascular, arteries, veins; RCT. To find additional studies, we also conducted author searches for authors with known expertise in peer-support research, and we searched references in published articles and the WHO statement on peer support in diabetes management [17]. We also reviewed relevant recent systematic reviews of interventions targeting lifestyle changes conducted in adults affected with diabetes to check for any additional missed studies [18-21]. Two reviewers (S.P. and R.J.K) independently screened all the citations, and two additional reviewers (T.R. and V.C.) confirmed their eligibility.

\section{Quality assessment}

Study quality was assessed using the Cochrane collaboration's risk of bias tool and checked for inter-rater comparability by two authors (S.P. and E.L.) [22].

\section{Data extraction}

One author (S.P.) created a codebook to include all variables of interest, which was reviewed by three other authors (E.L., T.R., and V.C.) before data extraction. Data were extracted independently by two authors (S.P. and E.L.). One additional author (T.R.) confirmed the extraction accuracy of numerical outcome data. We extracted data on study setting, intervention characteristics and multiple participant and peer characteristics. Blood pressure, cholesterol levels, BMI, physical activity, diet and smoking means and measures of statistical variation were extracted at baseline and study conclusion.

\section{Data synthesis and analysis}

Statistical analysis was performed using Comprehensive Meta-analysis Software version 3 (Biostat Inc., Englewood, NJ). The standardized mean difference in outcomes between peer support intervention group and control group was calculated using the DerSimonian and Laird random-effects model [23]. The standardized mean difference effect size expresses the difference in means between intervention and control groups in terms of their shared standard deviation [24]. We used change from baseline values for analysis and assumed a correlation coefficient of 0.5 between initial and final values [25]. We considered a $p$ value of $<0.05$ as statistically significant and calculated $95 \%$ confidence intervals (CI). Heterogeneity was evaluated by the $\mathrm{Q}$ statistic with a $p$-value of $<0.10$ indicating significant heterogeneity. The proportion of unexplained heterogeneity was described using the $\mathrm{I}^{2}$ statistics with $\mathrm{I}^{2}$ values $>75 \%$ indicating significant heterogeneity, $\mathrm{I}^{2}>50 \%$ indicating substantial heterogeneity, and $\mathrm{I}^{2}>30 \%$ indicating moderate heterogeneity [26]. We planned moderator analyses when ten or more studies were measuring the specified outcome. We conducted moderator analyses using meta-regression. Funnel plots and Eggers regression were used to assess publication bias [27].

\section{Results}

Study selection

We retrieved 438 citations from database searches and database author searches. We examined 37 full articles after removing duplicates and reviewing 233 abstracts. Despite our broader search, all retrieved citations were in English. Of the 37 full articles, 16 studies met the inclusion criteria. All disagreements were discussed and resolved to achieve $100 \%$ consensus for article selection (with four raters) and data abstraction (with three raters). Figure 1 shows the flow diagram of the literature search [28]. Of the 16 studies, 12 studies reported systolic BP outcomes, nine studies reported diastolic BP, eight studies reported total cholesterol, five reported LDL cholesterol outcomes, nine studies reported BMI outcomes, eight studies reported physical activity outcomes, six studies reported diet outcomes and one study reported smoking outcomes. All but one study ranged from 6 weeks to 12 months in duration of intervention and follow-up. Table 1 shows study characteristics.

\section{Risk of Bias and publication Bias}

Most included studies mentioned methods of randomization and allocation concealment, but none of the studies blinded participants. The risk of bias assessment for included studies is shown in Additional file 1. The outcomes and the quality of the studies were not interrelated. For all the outcomes examined with a metaanalysis, Funnel plots and Egger regression tests did not show any publication bias.

\section{Peer support effect on blood pressure}

For a total of 3243 participants, the overall pooled effect of peer-support interventions on systolic BP was a standardized mean difference of 0.107 (CI 0.018 to 0.195 ; $p=0.02, I^{2} 34.47 \%$ ), which translated to improvement in systolic BP of $2.07 \mathrm{mmHg}$ (CI 0.35 to 3.79 ) where the pooled mean baseline systolic BP was $137 \mathrm{mmHg}$ (Fig. 2 and Table 2). Meta-regression did not show any interaction between the baseline systolic BP and effect sizes (See Additional file 2). However, in all but one study, baseline systolic BP was in the range of 121 to 144 . In one study, the average baseline systolic BP was 152 [29]. A funnel plot and the Egger regression test did not show any publication bias (See Additional file 3). 


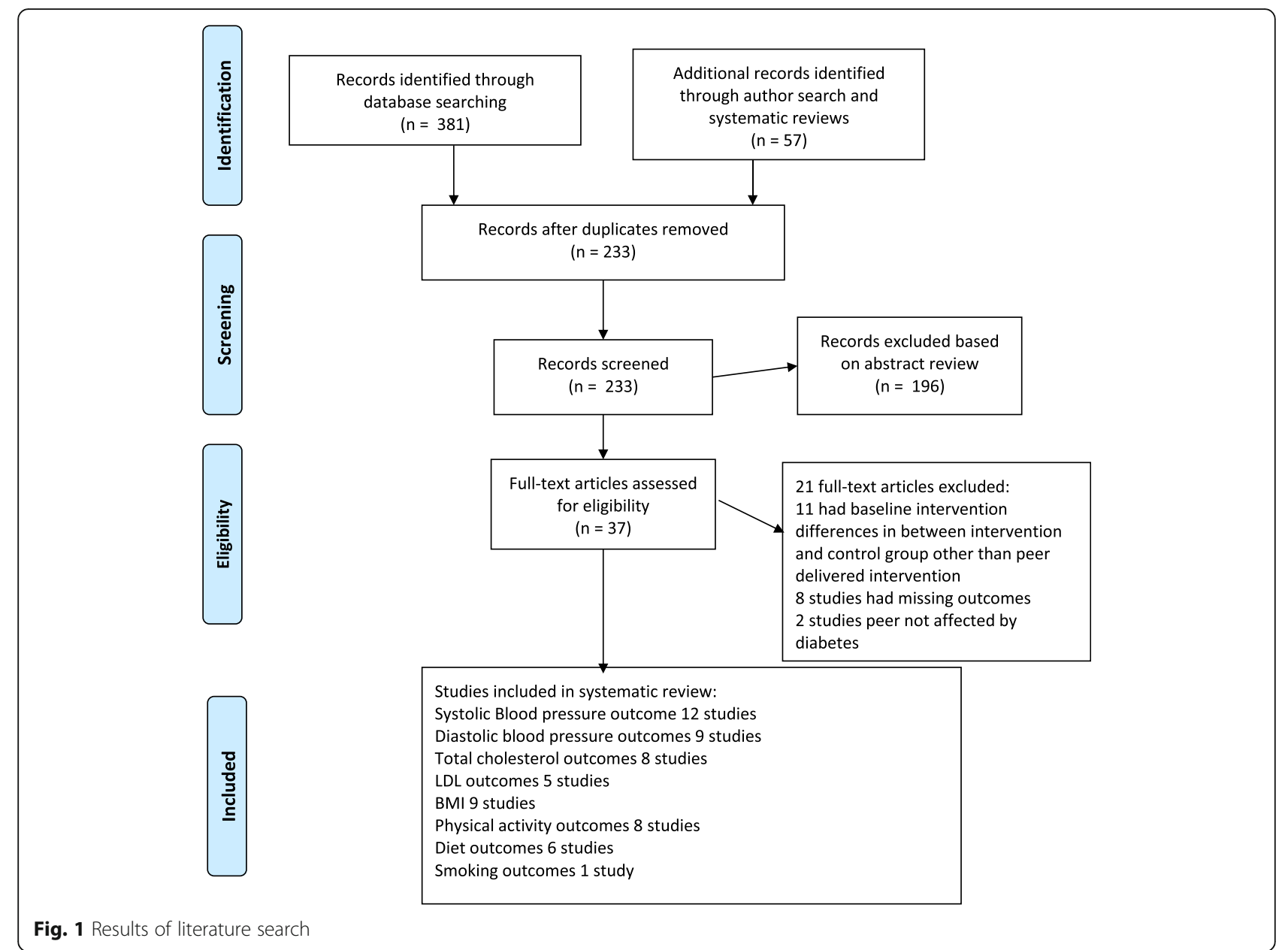

Meta-regression did not show any interaction between study duration and effect sizes (See Additional file 4).

There was no significant effect of peer support interventions on diastolic blood pressure (Table 2 and Additional file 5).

Peer support effect on cholesterol, BMI, physical activity, diet, and smoking

Meta-analysis of included studies did not show a significant pooled effect of peer support on total cholesterol, LDL-cholesterol, BMI, or physical activity. (Table 2 and See Additional file 6, Additional file 7, Additional file 8, Additional file 9). Physical activity was measured using varying instruments in included studies. Two studies measured physical activity with an accelerometer or pedometer, two studies used a physical activity scale measuring minutes of aerobic exercise per week, and four studies used the Summary of Diabetes Self-Care Activities (SDSCA) scale to measure physical activity (See Table 1). The effect of peer support on diet could not be summarized quantitatively due to varying dietary outcome measurements (e.g., total calories, calories from fat, or, fruit and vegetable intake). Four studies used the SDSCA to assess healthy diet and food and vegetable consumption in the past week [30-33]. One study utilized a series of three-day telephone-administered recalls of food intake, and another study used three-day food diaries and questionnaires [29, 34]. None of the studies showed significant differences in dietary intake between intervention and control groups. Only one study looked at the effect of a peer support intervention on smoking in adults with diabetes and did not show any significant difference between the peer support intervention group and the control group [30].

\section{Discussion}

The CDC cost-effectiveness group has reported that intensified hypertension control in adults with diabetes leads to reduced costs and better health outcomes whereas intensified glucose and cholesterol control leads to increased costs and improved outcomes [35]. In this review, peer support interventions were associated with a small but statistically significant improvement in systolic blood pressure with low-moderate heterogeneity of 


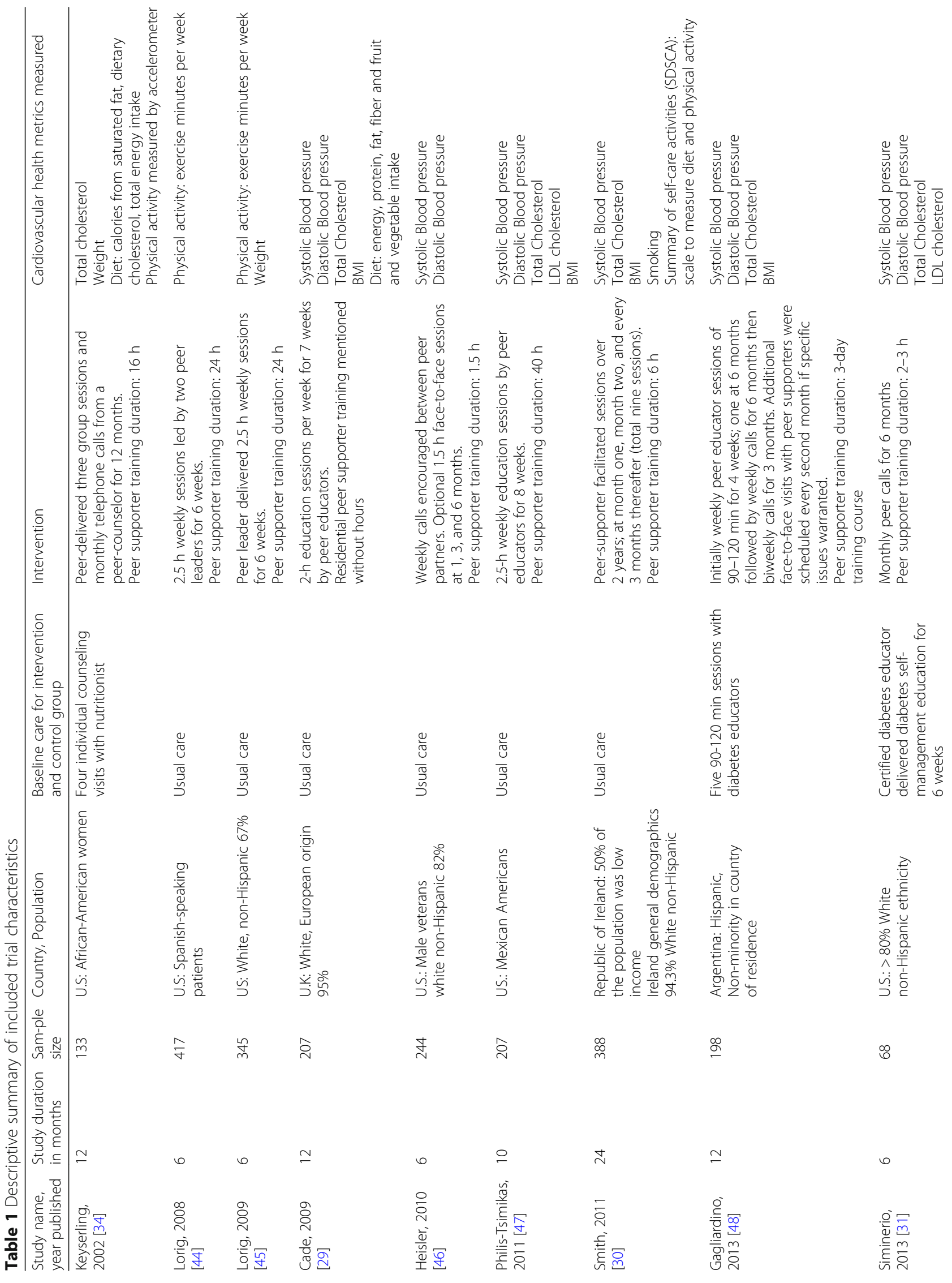




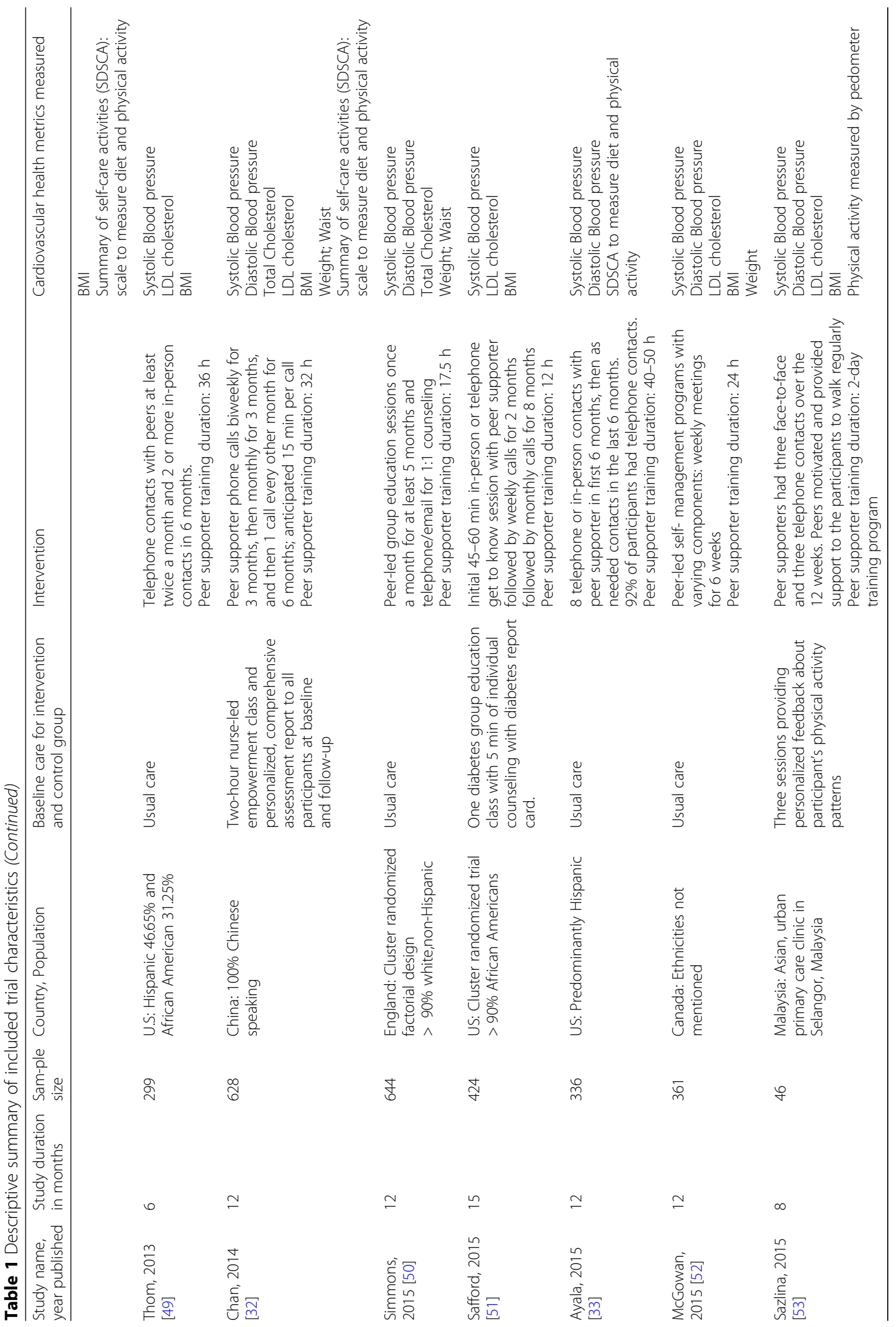




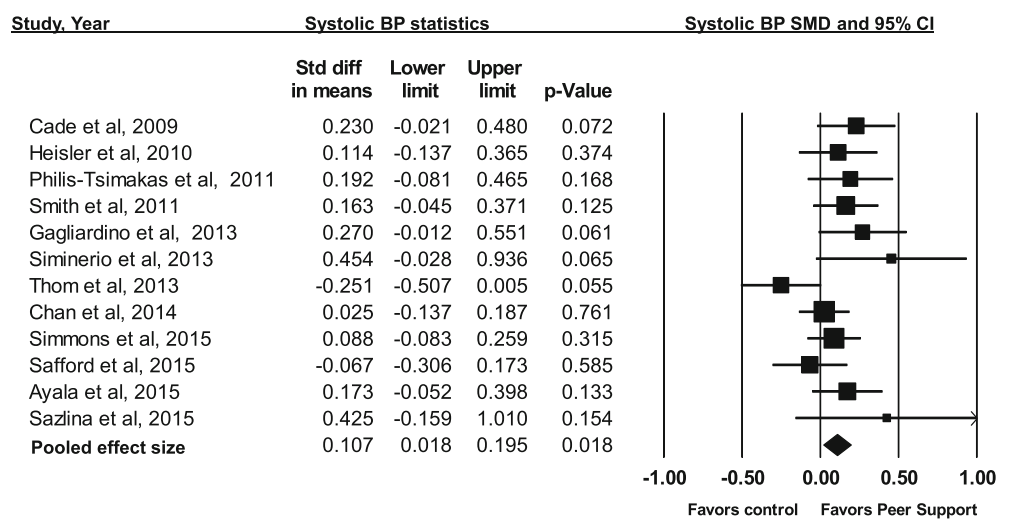

Fig. 2 Effect of peer support interventions on systolic blood pressure in adults with diabetes. SMD = Standardized mean difference; Systolic BP = systolic blood pressure. P $35.75 \%$, p for heterogeneity $=0.113$

results across studies despite the pooled baseline systolic $\mathrm{BP}$ being less than $140 \mathrm{mmHg}$. Despite baseline systolic blood pressures being $<140$ in most subjects in our meta-analysis, the improvement in systolic BP is particularly relevant with new evidence and guidelines that set a lower BP target of $<130 / 80$ in patients with diabetes [36]. The effect size of $2 \mathrm{mmHg}$ improvement is consistent with improvements seen with behavioral counseling interventions to promote a healthy lifestyle and reduce cardiovascular risk factors in a systematic review for the USPSTF [37]. Even though this improvement in systolic BP is small, at the population level it would be clinically relevant if sustained over time. For example, a $2 \mathrm{~mm}$ decrease in systolic blood pressure is associated with mortality reductions of $6 \%$ due to stroke, $4 \%$ due to coronary heart disease and 3\% in total mortality [38]. Peer-delivered interventions might be a feasible alternative for hypertension and diabetes self-management education in places with limited professional resources.
We did not find any significant effects of peer support interventions on any other cardiovascular disease risk factors except for systolic BP. One potential reason might be that peer intervention trials in patients affected with diabetes frequently targeted glucose control while participants had normal or only mildly abnormal baseline values of blood pressure, cholesterol, and BMI. Peer support interventions that specifically target CVD risk factors besides glycemic control in adults with diabetes need to be designed and tested. Even though the results were statistically non-significant, there was a positive effect of peer support interventions on total cholesterol with low heterogeneity of results noted across studies. Our meta-analysis may not have been powered sufficiently to detect a difference in total cholesterol between the peer intervention group and the control group, especially since the baseline total cholesterol was completely normal. Following completion of a study, consideration of confidence intervals is the most appropriate way to

Table 2 Results of peer support intervention effects on cardiovascular health outcomes

\begin{tabular}{|c|c|c|c|c|c|c|c|c|c|}
\hline Outcome & $\begin{array}{l}\text { Number } \\
\text { of studies }\end{array}$ & $\begin{array}{l}\text { Pooled effect } \\
\text { size }(S M D)^{a}\end{array}$ & $95 \% \mathrm{Cl}$ & $\begin{array}{l}\text { Baseline } \\
\text { pooled mean }\end{array}$ & $\begin{array}{l}\text { Pooled effect } \\
\text { size in original } \\
\text { metric }\end{array}$ & $\begin{array}{l}95 \% \mathrm{Cl} \text { in } \\
\text { original metric }\end{array}$ & $\begin{array}{l}p \text {-value } \\
\text { for SMD }\end{array}$ & $P^{2}(\%)$ & $\begin{array}{l}\text { Publication bias: } \\
\text { p-value of Egger } \\
\text { Regression test }\end{array}$ \\
\hline $\begin{array}{l}\text { Systolic Blood } \\
\text { pressure }\end{array}$ & 12 & 0.107 & 0.018 to 0.195 & $137 \mathrm{~mm} \mathrm{hg}$ & $2.07 \mathrm{~mm} \mathrm{hg}$ & 0.35 to $3.79 \mathrm{~mm} \mathrm{hg}$ & 0.02 & 34.47 & 0.15 \\
\hline $\begin{array}{l}\text { Diastolic Blood } \\
\text { Pressure }\end{array}$ & 9 & 0.039 & -0.086 to 0.164 & 77 mm hg & $0.42 \mathrm{~mm}$ hg & -0.94 to $1.79 \mathrm{~mm} \mathrm{hg}$ & 0.5 & 49.08 & 0.6 \\
\hline $\begin{array}{l}\text { Total } \\
\text { Cholesterol }\end{array}$ & 8 & 0.058 & -0.022 to 0.138 & $181 \mathrm{mg} / \mathrm{dL}$ & $2.61 \mathrm{mg} / \mathrm{dL}$ & -0.99 to $6.21 \mathrm{md} / \mathrm{dl}$ & 0.1 & 0.00 & 0.2 \\
\hline $\begin{array}{l}\mathrm{LDL} \\
\text { cholesterol }\end{array}$ & 5 & $-0.008^{b}$ & -0.124 to 0.109 & 107.85 mg/dl & $-0.28 \mathrm{mg} / \mathrm{dl}$ & -4.41 to $3.87 \mathrm{mg} / \mathrm{dl}$ & 0.8 & 8.47 & 0.2 \\
\hline BMI & 9 & 0.017 & -0.071 to 0.104 & 31.27 & 0.11 & -0.48 to 0.7 & 0.7 & 0.00 & 0.9 \\
\hline $\begin{array}{l}\text { Physical } \\
\text { activity }\end{array}$ & 8 & 0.019 & -0.068 to 0.106 & $N / A^{c}$ & $N / A^{c}$ & & 0.6 & 0.00 & 0.07 \\
\hline
\end{tabular}

apooled effect in terms of standardized mean difference (SMD) which is the difference in means between intervention and control participants in terms of their standard deviations

${ }^{b}$ negative sign indicates intervention effect favored control group

${ }^{c}$ Not Applicable since physical activity could not be converted to original metric due to diverse measurement scales used in included studies

Diet and Smoking outcomes could not be summarized quantitatively. No significant differences were observed for diet and smoking outcomes between groups 
view the potential for a clinically important difference with a larger study [39]. For BMI we found an effect size estimate of 0.11 with a confidence interval that includes the null effect, however, with an upper confidence limit for BMI of 0.7, a larger study might demonstrate an important difference. Similarly for diastolic BP we found an effect size of $0.42 \mathrm{mmHg}$, but with an upper confidence limit of 1.79, a larger study might also demonstrate an important difference. For total cholesterol, we found a difference of $2.61 \mathrm{mg} / \mathrm{dl}$ in total cholesterol with an upper confidence limit of $6.21 \mathrm{mg} / \mathrm{dl}$. For perspective, USPSTF recommendations on behavioral counseling to prevent cardiovascular disease in adults were based on improvement in BMI of at least 0.3, improvement in diastolic BP of at least $1.1 \mathrm{mmHg}$ and improvement in total cholesterol of at least $6.56 \mathrm{mg} / \mathrm{dl}$ [40]. Further larger studies are needed potentially to detect improvements in BMI and diastolic BP of at least these levels; however, clinically significant improvements in total cholesterol might be challenging to achieve.

In a few studies not limited to adults with diabetes, peer support intervention effects on cardiovascular disease risk factors have shown promise. Recently, a Spanish randomized controlled trial studying the effect of peer support interventions on self-control of unhealthy behaviors in individuals at risk of cardiovascular disease showed improvement in cardiovascular health after 1 year, specifically in smoking cessation [41]. Another study of peer-led education for secondary prevention among predominantly minority stroke survivors led to improved systolic BP control, but no difference in control of cholesterol [42]. Peer support interventions may be a feasible way to initiate and maintain cardiovascular health in large populations; however further studies in persons with higher baseline cardiovascular risk factors are required.

\section{Limitations}

Because we evaluated peer support intervention trials in adults affected by diabetes, most of the included trials may have targeted improving diabetes control rather than overall cardiovascular health. Additionally, we found few studies reporting some outcomes, specifically LDL, and smoking outcomes; this resulted in lower power to detect significant differences between groups. Moreover, most of the studies included in our review had an intervention duration between 6 weeks to 12 months (only one study included a longer duration); it would be challenging to demonstrate a positive effect of behavioral interventions over such a short duration, especially when most study participants had normal or mildly abnormal baseline values of cardiovascular disease risk factors. Another limitation of our study was that we used the outcomes at study conclusion, therefore, we have lumped changes between baseline and multiple different follow-up times ranging from 6 months to 24 months. However, in a meta-regression with our systolic blood pressure results, we did not find an interaction of effect size and intervention duration. Most studies measured diet and physical activity using the SDSCA scale which is a self- report instrument that has been validated using multiple methods of self-report [43]. Similarly, only two studies measured physical activity using accelerometer and pedometer data while six studies used self-report scales to measure physical activity. We acknowledge there is always the risk of recall bias and social desirability with self-report measures. Blinding is not possible in peer support intervention trials since a peer needs to deliver the intervention to the participants; however, only two of all the included studies in our review blinded outcomes assessors. One additional study limitation is the possibility we missed studies reporting cardiovascular disease risk factors in adults with diabetes.

\section{Conclusions}

In adults affected with diabetes, peer support interventions lead to a small improvement in systolic blood pressure when mean baseline systolic blood pressure levels were just minimally elevated according to new AHA guideline standards. The effectiveness of peer support interventions for improving overall cardiovascular disease risk factors needs to be further studied in adults affected with diabetes who have high-risk baseline cardiovascular disease risk factors.

\section{Additional files}

Additional file 1: Quality assessment of the included studies with Cochrane's risk of bias tool. (DOCX $25 \mathrm{~kb}$ )

Additional file 2: Regression of standardized difference in means of included studies on baseline systolic blood pressure. (PDF 5 kb)

Additional file 3: Funnel plot of standard error by standardized difference in means for systolic blood pressure. (PDF 5 kb)

Additional file 4: Regression of standardized difference in means of included studies on Study duration. (PDF $84 \mathrm{~kb}$ )

Additional file 5: Effect of peer support interventions on diastolic blood pressure in adults with diabetes. SMD = Standardized mean difference; Diastolic BP $=$ systolic blood pressure. P $^{2} 49.07 \%$, p for heterogeneity $=0.05$. (PDF $8 \mathrm{~kb}$ )

Additional file 6: Effect of peer support interventions on cholesterol in adults with diabetes. SMD $=$ standardized mean difference; $\digamma^{2} 0.00 \%$, p for heterogeneity $=0.7$. (PDF $8 \mathrm{~kb})$

Additional file 7: Effect of peer support interventions on LDL cholesterol in adults with diabetes. SMD $=$ standardized mean difference; $P^{2} 0.00 \%$, p for heterogeneity $=0.819$. (PDF $8 \mathrm{~kb}$ )

Additional file 8: Effect of peer support interventions on BMI in adults with diabetes. $\mathrm{SMD}=$ standardized mean difference; $\mathrm{BMI}=$ Body Mass Index; $P^{2}$ 0.00\%, p for heterogeneity $=0.9$. (PDF $86 \mathrm{~kb}$ )

Additional file 9: Effect of peer support interventions on physical activity in adults with diabetes. SMD = standardized mean difference; $P^{2} 0.00 \%$, p for heterogeneity $=0.47$. (PDF $8 \mathrm{~kb}$ ) 


\section{Abbreviations}

AAFP: American academy of family physicians; AHA: American Heart Association; BMI: Body mass index; BP: Blood pressure; CDC: Centers for disease control and prevention; Cl: Confidence intervals; CVD: Cardiovascular disease; HbA1C: Hemoglobin A1C; LDL cholesterol: Low-density lipoprotein cholesterol; RCTs: Randomized controlled trials; SDSCA: Summary of diabetes self-care activities scale; SMD: Standardized mean difference; USPSTF: U.S. preventive services task force; WHO: World Health Organization

\section{Acknowledgements}

Not Applicable.

\section{Funding}

No external funding was received. The University of Missouri, Department of Family and Community Medicine funded the cost of software used for statistical analysis.

\section{Availability of data and materials}

Not applicable to this article as no datasets were generated during the current study. We used data from published studies.

\section{Authors' contributions}

S.J.P conceptualized and designed the review, screened articles, conducted and interpreted data analysis, and drafted and revised the article. T.R. screened articles, designed the review, assisted in data analysis and interpretation, and revised the manuscript. RJ.K. screened articles, assisted in design, drafted and revised the manuscript. E.J.L. abstracted data, assisted in design, drafted and revised the manuscript. D.R.M. screened articles, assisted with design, and drafted and revised the manuscript. V.S.C. screened articles, assisted in design, assisted in data analysis and interpretation, and drafted and revised the manuscript. All authors read and approved the final manuscript.

\section{Authors' information}

Our author team has expertise in various aspects of cardiovascular disease risk factors; R. J. Koopman has published numerous articles on diabetes prevalence, Todd Ruppar and Vicki Conn have expertise in physical activity and cardiovascular diseases, and David Mehr has participated in several studies focused on improving chronic disease care. Additionally, Vicki Conn and Todd Ruppar are the directors of Meta-Analysis Research Center at the University of Missouri and have conducted several $\mathrm{NIH}$-funded meta-analyses. The primary author is a well-trained clinician researcher with interests in cardiovascular health interventions and has previously published a peer support intervention meta-analysis in one of the premiere Primary Care research journals, Annals of Family Medicine.

\section{Ethics approval and consent to participate}

Not applicable since published articles were reviewed.

\section{Consent for publication}

Not Applicable.

\section{Competing interests}

The authors declare that they have no competing interests.

\section{Publisher's Note}

Springer Nature remains neutral with regard to jurisdictional claims in published maps and institutional affiliations.

\author{
Author details \\ ${ }^{1}$ Curtis W. and Ann H. Long Department of Family and Community \\ Medicine, University of Missouri, MA306 Medical Sciences Building, DC032.00 \\ Columbia, MO 65212, USA. ${ }^{2}$ College of Nursing, Rush University Medical \\ Center, Chicago, IL, USA. ${ }^{3}$ Sinclair School of Nursing, University of Missouri, \\ Columbia, MO, USA \\ Received: 3 July 2017 Accepted: 15 March 2018 \\ Published online: 23 March 2018

\section{References} \\ 1. Emerging Risk Factors Collaboration, Sarwar N, Gao P, Seshasai SR, Gobin R, \\ Kaptoge S, Di AE IE, Lawlor DA, Selvin E, et al. Diabetes mellitus, fasting
}

blood glucose concentration, and risk of vascular disease: a collaborative meta-analysis of 102 prospective studies. Lancet. 2010;375:2215-22.

2. Huang ES, Meigs JB, Singer DE. The effect of interventions to prevent cardiovascular disease in patients with type 2 diabetes mellitus. Am J Med. 2001;111:633-42.

3. My life check: life's simple 7 [http://mylifecheck.heart.org/].

4. Lloyd-Jones DM, Hong Y, Labarthe D, Mozaffarian D, Appel LJ, Van Horn L, Greenlund K, Daniels S, Nichol G, Tomaselli GF, et al. Defining and setting national goals for cardiovascular health promotion and disease reduction. Circulation. 2010;121:586

5. Folsom AR, Yatsuya H, Nettleton JA, Lutsey PL, Cushman M, Rosamond WD. ARIC S, I: community prevalence of ideal cardiovascular health, by the American Heart Association definition, and relationship with cardiovascular disease incidence. J Am Coll Cardiol. 2011;57:1690-6.

6. Kulshreshtha A, Vaccarino V, Judd SE, Howard VJ, McClellan WM, Muntner P, Hong Y, Safford MM, Goyal A, Cushman M. Life's simple 7 and risk of incident stroke: the reasons for geographic and racial differences in stroke study. Stroke. 2013;44:1909-14.

7. Younus A, Aneni EC, Spatz ES, Osondu CU, Roberson L, Ogunmoroti O, Malik R, Ali SS, Aziz M, Feldman T, et al. A systematic review of the prevalence and outcomes of ideal cardiovascular health in US and non-US populations. Mayo Clin Proc. 2016;91:649-70.

8. Artinian NT, Fletcher GF, Mozaffarian D, Kris-Etherton P, Van HL, Lichtenstein AH, Kumanyika S, Kraus WE, Fleg JL, Redeker NS, et al. Interventions to promote physical activity and dietary lifestyle changes for cardiovascular risk factor reduction in adults: a scientific statement from the American Heart Association. Circulation. 2010;122:406-41.

9. Parry M, Watt-Watson J. Peer support intervention trials for individuals with heart disease: a systematic review. Eur J Cardiovasc Nurs. 2010;9:57-67.

10. Patil SJ, Ruppar T, Koopman RJ, Lindbloom EJ, Elliott SG, Mehr DR, Conn VS. Peer-support interventions for adults with diabetes: a meta-analysis of hemoglobin A1c outcomes. Ann Fam Med. 2016;14:540-51.

11. Qi L, Liu Q, Qi X, Wu N, Tang W, Xiong H. Effectiveness of peer support for improving glycaemic control in patients with type 2 diabetes: a metaanalysis of randomized controlled trials. BMC Public Health. 2015;15:471.

12. Zhang $X$, Yang $S$, Sun $K$, Fisher $E B$, Sun $X$. How to achieve better effect of peer support among adults with type 2 diabetes: a meta-analysis of randomized clinical trials. Patient Educ Couns. 2016:99:186-97.

13. What is peer support? [http://peersforprogress.org/learn-about-peersupport/what-is-peer-support/].

14. Goldman ML, Ghorob A, Eyre SL, Bodenheimer T. How do peer coaches improve diabetes care for low-income patients?: a qualitative analysis. Diabetes Educ. 2013:39:800-10.

15. Mosack KE, Patterson L, Brouwer AM, Wendorf AR, Ertl K, Eastwood D, Morzinski J Fletcher $\mathrm{K}$, Whittle J. Evaluation of a peer-led hypertension intervention for veterans: impact on peer leaders. Health Educ Res. 2013;28:426-36.

16. Liberati A, Altman DG, Tetzlaff J, Mulrow C, Gotzsche PC, loannidis JP, Clarke M, Devereaux PJ, Kleijnen J, Moher D. The PRISMA statement for reporting systematic reviews and meta-analyses of studies that evaluate health care interventions: explanation and elaboration. Ann Intern Med. 2009;151:W65-94.

17. Peer support programmes in diabetes: report of a WHO Consultation [http://www.who.int/diabetes/publications/Diabetes_final_13_6.pdf].

18. Avery L, Flynn D, van Wersch A, Sniehotta FF, Trenell Ml. Changing physical activity behavior in type 2 diabetes: a systematic review and meta-analysis of behavioral interventions. Diabetes Care. 2012;35:2681-9.

19. Foster G, Taylor SJ, Eldridge SE, Ramsay J, Griffiths CJ. Self-management education programmes by lay leaders for people with chronic conditions. Cochrane Database Syst Rev. 2007, Issue 4. Art. No.: CD005108. https://doi. org/10.1002/14651858.CD005108.pub2.

20. Norris SL, Zhang X, Avenell A, Gregg E, Brown T, Schmid CH, Lau J. Longterm non-pharmacological weight loss interventions for adults with type 2 diabetes mellitus. Cochrane Database Syst Rev. 2005, Issue 2. Art. No.: CD004095. https://doi.org/10.1002/14651858.CD004095.pub2.

21. Webel AR, Okonsky J, Trompeta J, Holzemer WL. A systematic review of the effectiveness of peer-based interventions on health-related behaviors in adults. Am J Public Health. 2010;100:247-53.

22. Higgins JPT, Altman DG, Sterne JAC. Assessing risk of bias in included studies. In: Higgins JPT, Green S, editors. Cochrane handbook for systematic reviews of interventions. Version 5.1.0 ed. Oxford: Cochrane Collaboration; 2011

23. DerSimonian R, Laird N. Meta-analysis in clinical trials. Control Clin Trials. 1986:7:177-88. 
24. Lipsey M. Identifying interesting variables and analysis opportunities. In: Cooper HM, Hedges LV, Valentine JC, editors. The handbook of research synthesis and meta-analysis. 2nd ed. New York: Russell Sage Foundation; 2009. p. 147-58.

25. Follmann D, Elliott P, Suh I, Cutler J. Variance imputation for overviews of clinical trials with continuous response. J Clin Epidemiol. 1992;45:769-73.

26. Higgins JP, Thompson SG, Deeks JJ, Altman DG. Measuring inconsistency in meta-analyses. BMJ. 2003;327:557-60.

27. Egger M, Davey SG, Schneider M, Minder C. Bias in meta-analysis detected by a simple, graphical test. BMJ. 1997;315:629-34.

28. Moher D, Liberati A, Tetzlaff J, Altman DG. Preferred reporting items for systematic reviews and meta-analyses: the PRISMA statement. PLoS Med. 2009;6:e1000097.

29. Cade JE, Kirk SF, Nelson P, Hollins L, Deakin T, Greenwood DC, Harvey EL. Can peer educators influence healthy eating in people with diabetes? Results of a randomized controlled trial. Diabet Med. 2009;26:1048-54.

30. Smith SM, Paul G, Kelly A, Whitford DL, O'Shea E, O'Dowd T. Peer support for patients with type 2 diabetes: cluster randomised controlled trial. BMJ. 2011;342:d715

31. Siminerio L, Ruppert KM, Gabbay RA. Who can provide diabetes selfmanagement support in primary care? Findings from a randomized controlled trial. Diabetes Educ. 2013;39:705-13.

32. Chan JC, Sui Y, Oldenburg B, Zhang Y, Chung HH, Goggins W, Au S, Brown N, Ozaki R, Wong RY, et al. Effects of telephone-based peer support in patients with type 2 diabetes mellitus receiving integrated care: a randomized clinical trial. JAMA Intern Med. 2014;174:972-81.

33. Ayala GX, Ibarra L, Cherrington AL, Parada $H$, Horton $L$, Ji M, Elder JP. Puentes hacia una mejor Vida (bridges to a better life): outcome of a diabetes control peer support intervention. Ann Fam Med. 2015;13:S9-S17.

34. Keyserling TC, Samuel-Hodge CD, Ammerman AS, Ainsworth BE, HenriquezRoldan CF, Elasy TA, Skelly AH, Johnston LF, Bangdiwala SI. A randomized trial of an intervention to improve self-care behaviors of African-American women with type 2 diabetes: impact on physical activity. Diabetes Care. 2002:25:1576-83.

35. CDC Diabetes Cost-effectiveness Group. Cost-effectiveness of intensive glycemic control, intensified hypertension control, and serum cholesterol level reduction for type 2 diabetes. JAMA. 2002;287:2542-51.

36. Whelton PK, Carey RM, Aronow WS, Casey DE, Jr., Collins KJ, Dennison HC, DePalma SM, Gidding S, Jamerson KA, Jones DW et al.: 2017 ACC/AHA/ AAPA/ABC/ACPM/AGS/APhA/ASH/ASPC/NMA/PCNA Guideline for the Prevention, Detection, Evaluation, and Management of High Blood Pressure in Adults: A Report of the American College of Cardiology/American Heart Association Task Force on Clinical Practice Guidelines. Hypertension 2017, DOI: https://doi.org/10.1161/HYP.0000000000000065.

37. Lin JS, O'Connor E, Evans CV, Senger CA, Rowland MG, Groom HC. Behavioral counseling to promote a healthy lifestyle in persons with cardiovascular risk factors: a systematic review for the U.S. preventive services task force. Ann Intern Med. 2014;161:568-78.

38. Whelton PK, He J, Appel LJ, Cutler JA, Havas S, Kotchen TA, Roccella EJ, Stout R, Vallbona C, Winston MC, et al. Primary prevention of hypertension: clinical and public health advisory from the National High Blood Pressure Education Program. JAMA. 2002;288:1882-8.

39. Goodman SN, Berlin JA. The use of predicted confidence intervals when planning experiments and the misuse of power when interpreting results. Ann Intern Med. 1994:121:200-6.

40. Lin JS, O'Connor E, Whitlock EP, Beil TL, Zuber SP, Perdue LA, Plaut D, Lutz K. Behavioral counseling to promote physical activity and a healthful diet to prevent cardiovascular disease in adults: update of the evidence for the U.S. preventive services task force. In: Evidence synthesis no. 79. AHRQ publication no. 11-05149-EF-1. Agency for Health Care Research and Quality: Rockville, MD; 2010.

41. Gomez-Pardo E, Fernandez-Alvira JM, Vilanova M, Haro D, Martinez R, Carvajal I, Carral V, Rodriguez C, de Miguel M, Bodega P, et al. A comprehensive lifestyle peer group-based intervention on cardiovascular risk factors: the Randomized Controlled Fifty-Fifty Program. J Am Coll Cardiol. 2016;67:476-85.

42. Kronish IM, Goldfinger JZ, Negron R, Fei K, Tuhrim S, Arniella G, Horowitz $C R$. Effect of peer education on stroke prevention: the prevent recurrence of all inner-city strokes through education randomized controlled trial. Stroke. 2014:45:3330-6
43. Toobert DJ, Hampson SE, Glasgow RE. The summary of diabetes self-care activities measure: results from 7 studies and a revised scale. Diabetes Care. 2000;23:943-50.

44. Lorig K, Ritter PL, Villa F, Piette JD. Spanish diabetes self-management with and without automated telephone reinforcement: two randomized trials. Diabetes Care. 2008;31:408-14.

45. Lorig K, Ritter PL, Villa FJ, Armas J. Community-based peer-led diabetes selfmanagement: a randomized trial. Diabetes Educ. 2009;35:641-51.

46. Heisler M, Vijan S, Makki F, Piette JD. Diabetes control with reciprocal peer support versus nurse care management: a randomized trial. Ann Intern Med. 2010:153:507-15.

47. Philis-Tsimikas A, Fortmann A, Lleva-Ocana L, Walker C, Gallo LC. Peer-led diabetes education programs in high-risk Mexican Americans improve glycemic control compared with standard approaches: a project Dulce promotora randomized trial. Diabetes Care. 2011:34:1926-31.

48. Gagliardino JJ, Arrechea V, Assad D, Gagliardino GG, Gonzalez L, Lucero S, Rizzuti L, Zufriategui Z, Clark C Jr. Type 2 diabetes patients educated by other patients perform at least as well as patients trained by professionals. Diabetes Metab Res Rev. 2013;29:152-60.

49. Thom DH, Ghorob A, Hessler D, De VD, Chen E, Bodenheimer TA. Impact of peer health coaching on glycemic control in low-income patients with diabetes: a randomized controlled trial. Ann Fam Med. 2013;11:137-44.

50. Simmons D, Prevost AT, Bunn C, Holman D, Parker RA, Cohn S, Donald S, Paddison CAM, Ward C, Robins P, et al. Impact of community based peer support in type 2 diabetes: a cluster randomised controlled trial of individual and/or group approaches. PLoS One. 2015;10:e0120277.

51. Safford MM, Andreae S, Cherrington AL, Martin MY, Halanych J, Lewis M, Patel A, Johnson E, Clark D, Gamboa C, et al. Peer coaches to improve diabetes outcomes in rural Alabama: a cluster randomized trial. Ann Fam Med. 2015;13:S18-26.

52. McGowan P. The relative effectiveness of self-management programs for type 2 diabetes. Can J Diabetes. 2015;39:411-9.

53. Sazlina SG, Browning CJ, Yasin S. Effectiveness of personalized feedback alone or combined with peer support to improve physical activity in sedentary older Malays with type 2 diabetes: a randomized controlled trial. Front Public Health. 2015;3:178

\section{Submit your next manuscript to BioMed Central and we will help you at every step:}

- We accept pre-submission inquiries

- Our selector tool helps you to find the most relevant journal

- We provide round the clock customer support

- Convenient online submission

- Thorough peer review

- Inclusion in PubMed and all major indexing services

- Maximum visibility for your research

Submit your manuscript at www.biomedcentral.com/submit 